\title{
Multiresidue Determination of Endocrine Disrupting Compounds in Sewage Treatment Plants (SPE-HPLC-DAD)
}

\author{
Carla B. Vidal, ${ }^{\oplus a, b, c, d}$ Pablo G. A. Barbosa, ${ }^{e}$ Germana P. Pessoa, ${ }^{b}$ Patrícia C. Buarque, ${ }^{b}$ \\ José G. S. Nascimento, ${ }^{b}$ Antônio L. Farias Filho, ${ }^{b}$ Mário S. Paz, ${ }^{a}$ André B. dos Santos, ${ }^{b}$ \\ Rivelino M. Cavalcante ${ }^{f}$ and Ronaldo F. Nascimento ${ }^{\circledR} * a, b$
}

${ }^{a}$ Departamento de Química Analítica e Físico-Química, Universidade Federal do Ceará, Rua do Contorno, S/N, Campus do Pici, Bl. 940, 60451-970 Fortaleza-CE, Brazil

${ }^{b}$ Departamento de Engenharia Hidráulica e Ambiental, Universidade Federal do Ceará, Rua do Contorno, S/N, Campus do Pici, Bl. 713, 60451-970 Fortaleza-CE, Brazil

${ }^{c}$ Centro Universitário Fanor Wyden, Campus Dunas, R. Antônio Gomes Guimarães, 150, Papicu, 60191-195 Fortaleza-CE, Brazil

${ }^{d}$ Centro Universitário UniFametro, Campus Carneiro da Cunha, R. Carneiro da Cunha, 180, Jacarecanga, 60010-470 Fortaleza-CE, Brazil

eInstituto Federal de Educação, Ciência e Tecnologia do Ceará, Campus Sobral, Av. Doutor Guarani, 317, Derby Clube, 62042-030 Sobral-CE, Brazil

${ }^{f}$ Laboratório de Contaminantes Orgânicos (LACOr), Instituto de Ciências do Mar, Universidade Federal do Ceará (LABOMAR-UFC), Av. Abolição, 3207-Meireles, 60165-081 Fortaleza-CE, Brazil

\begin{abstract}
This work focuses on the validation and application of solid phase extraction followed by high-performance liquid chromatography (SPE-HPLC) analysis of important endocrine disruptors compounds (EDC) from different classes in highly complex wastewater matrix. The endocrine disruptors investigated included three different categories: pharmaceuticals (sulfamethoxazole (SMZ), trimethoprim (TMP) and diclofenac (DCF)), hormones (estrone (E1), 17 $\alpha$-ethinylestradiol (EE2) and 17ß-estradiol (E2)) and plastic materials (bisphenol A (BPA)). The method involves pre-concentration by SPE using Strata-X extraction cartridges followed by HPLC coupled with diode array detector (DAD). As the assumption of homoscedasticity was met for analytical data, ordinary linear regression procedure was applied to the data. The method was considered validated for $7 \mathrm{EDC}$ after consistent evaluation of the key analytical parameters. Recoveries were ranged from 52.3 to $179.6 \%$. Limits of quantification were in the range $6.0-0.4 \mu \mathrm{g} \mathrm{L}^{-1}$. The described method was applied to evaluate the occurrence and removal efficiency of EDC in two biological sewage treatment plants (STPs). The influent mean concentrations of E1, E2 and EE2 hormones were 79.54; 175.09 and 102.19 $\mu \mathrm{g} \mathrm{L}^{-1}$, respectively, while for SMZ, TMP, DCF and BPA were $215.17 ; 187.01 ; 218.97$ and $87.12 \mu \mathrm{L} \mathrm{L}^{-1}$ for STP A, respectively. The efficiencies for the removal of EDCs ranged from 0 to $79.4 \%$.
\end{abstract}

Keywords: endocrine disruptors, wastewater, high-performance liquid chromatography, UASB, solid-phase extraction

\section{Introduction}

Endocrine disruptors compounds (EDC) are components or active ingredients of pharmaceuticals, personal care products, veterinary medicines, "lifestyle compounds",

*e-mail: ronaldo@ufc.br steroids, metabolic regulators, food additives, and therefore, these chemicals are from multiple sources, and hence they are on the recent list of new contaminant candidates from US Environment Protection Agency and European Commission. ${ }^{1-4}$

Most of technologies used in Brazilian's WWTPs (wastewater treatment plants) are conventional biological 
type, specially of stabilization ponds, activated sludge systems and anaerobic reactors, such as upflow anaerobic sludge blanket (UASB). However, several investigations have shown that EDC are frequently not removed during conventional biological wastewater treatment and also not biodegraded in the environment. ${ }^{5-8}$ Their insufficient removal from the WWTPs is mentioned as the major source of their release into environment. ${ }^{9,10}$

In the state of Ceará, biological processes are widely used, because of the great applicability, low capital and operational costs. However, there are still few studies on monitoring these compounds in sewage treatment plant effluents in northeastern Brazil, therefore, more studies on the determination and quantification of these compounds in these environmental matrices are essential. ${ }^{5}$

A wide range of methods, mainly based on liquid chromatography-mass spectrometry (LC-MS), gas chromatography-mass spectrometry (GC-MS), solid phase extraction liquid chromatography tandem mass spectrometry (SPE-LC-MS/MS) are being developed. .,9,11,12 Gas chromatography coupled to electron ionization (EI) mass spectrometry (MS) is both sensitive and selective for the determination of endocrine disruptors, however, derivatization of non-volatile and thermally labile endocrine disruptors is required prior to analysis, ${ }^{13}$ besides when analyzing contaminated samples, suppression of electrospray ionization is most likely to occur. ${ }^{14}$ This increases the overall analysis time and it may lead to errors to the analytical technique.

High-performance liquid chromatography (HPLC) instruments are one of the most popular and they are still widely applied to analyze these compounds because of their lower cost and greater robustness with sensitive method which can separate a wide variety of endocrine disruptor in variety matrices, some of which are not amenable to gas chromatography. ${ }^{6}$

Liquid chromatography with fluorescence detection has been reported to have a low limit of detection (LOD). However, the technique certainly requires derivatization to improve the fluorescence properties for detection. ${ }^{15}$ The use of diode array detector (DAD) as a detector for HPLC has proved to be a powerful tool in the determination and identification of compounds as it allows the online acquisition of their UV spectra. ${ }^{3,4,6-8}$ In addition, most of above mentioned methods are for one class of endocrine disruptors only. A challenge is presented in the simultaneous extraction and analysis of multiple classes of compounds.

The studies of selective and sensitive analytical methods are an important step to provide well founded data on the behavior of EDC in WWTPs. In order to optimize a treatment process or pre-treatment step so that the emission of undesired pollutants into the receiving waters is prevented, it is necessary more information obtained from analysis of influents and effluents of WWTPs. Based on the above, the goal of this paper is to develop and validate an SPE HPLC-DAD method for the qualitative and quantitative simultaneous determination of selected EDC in two two biological sewage treatment plants (STPs) as well as the evaluation of the occurrence of those EDC in two sewage treatment plants located in the state of Ceará, Brazil.

\section{Experimental}

\section{Reagents and materials}

The endocrine disruptors studied were: trimethoprim (TMP), sulfamethoxazole (SMZ), diclofenac (DCF), estrone (E1), 17 $\beta$-estradiol (E2), 17 $\alpha$-ethinylestradiol (EE2), and bisphenol-A (BPA). All compounds standards were of analytical grade (>99\%) and obtained from SigmaAldrich (St. Louis, MO, USA). The chemical structures of the endocrine disruptors included in this study are shown in Table 1. Stock solution of endocrine disruptors mixture was prepared in methanol and stored protected from light at $4{ }^{\circ} \mathrm{C}$. All used solvents were HPLC-grade supplied by Vetec (São Paulo, Brazil).

\section{Sample preparation and HPLC-DAD analyses}

SPE extraction was performed following the methodology of Pessoa et al. ${ }^{5}$ and qualitative and quantitative analyses of extracts collected were analyzed using HPLC.

The first step of sample preparation involved performing wastewater filtrations under vacuum through $0.45 \mu \mathrm{m}$ glass-fiber filters to remove suspended particulate matter and avoid SPE cartridge clogging. The $\mathrm{pH}$ of each sample was then adjusted to 3.0 by addition of $50 \%$ (v/v) $\mathrm{HCl}$, after which the analytes were extracted with a Speed Mate 12-port SPE vacuum manifold (Applied Separations, Allentown, PA, USA). The SPE cartridges were initially preconditioned with $10 \mathrm{~mL}$ of methanol, and subsequently with $10 \mathrm{~mL}$ of Milli-Q water ( $\mathrm{pH} 3$, Millipore, Bedford, MA, USA). The samples, typically $500 \mathrm{~mL}$, were then loaded onto the $500 \mathrm{mg}$ Strata-X cartridges (Phenomenex, Lane Cove, NSW, Australia) at a flow rate lower than $2 \mathrm{~mL} \mathrm{~min}^{-1}$. The cartridges were then dried for $30 \mathrm{~min}$ under vacuum and eluted with $8 \mathrm{~mL}$ of methanol. Extracts collected were analyzed using HPLC.

Qualitative and quantitative analyses were performed using a liquid chromatograph HPLC Shimadzu (20A prominence, Kyoto, Japan) with UV-DAD detector (SPD-M20A) $(215 \mathrm{~nm}), \mathrm{C} 18,5 \mu \mathrm{m}$ column, $250 \times 4.6 \mathrm{~mm}$ inner diameter 
Table 1. Physicochemical properties for the EDC studied

\begin{tabular}{|c|c|c|c|c|c|c|}
\hline $\mathrm{EDC}$ & Molecular formula & $\begin{array}{l}\text { Molecular weight / } \\
\left(\mathrm{g} \mathrm{mol}^{-1}\right)\end{array}$ & $\begin{array}{c}\text { Solubility at } 25^{\circ} \mathrm{C} / \\
\left(\mathrm{mg} \mathrm{L}^{-1}\right)\end{array}$ & $\log \mathrm{K}_{\mathrm{ow}}$ & $\mathrm{p} K_{\mathrm{a}}$ & Molecular structure \\
\hline SMZ & $\mathrm{C}_{10} \mathrm{H}_{11} \mathrm{~N}_{3} \mathrm{O}_{3} \mathrm{~S}$ & 253.28 & 610 & 0.89 & $\begin{array}{l}\text { (1) } 1.6 \\
\text { (2) } 5.7\end{array}$ & \\
\hline TMP & $\mathrm{C}_{14} \mathrm{H}_{18} \mathrm{~N}_{4} \mathrm{O}_{3}$ & 290.3 & 400 & 0.91 & 7.12 & \\
\hline DCF & $\mathrm{C}_{14} \mathrm{H}_{11} \mathrm{Cl}_{2} \mathrm{NO}$ & 296.14 & 2.4 & 4.51 & 4.2 & \\
\hline E1 & $\mathrm{C}_{18} \mathrm{H}_{22} \mathrm{O}_{2}$ & 270.37 & $0.8-12.4$ & 3.13 & 10.4 & \\
\hline E2 & $\mathrm{C}_{18} \mathrm{H}_{24} \mathrm{O}_{2}$ & 272.39 & $3.9-13.3$ & 4.01 & 10.4 & \\
\hline EE2 & $\mathrm{C}_{20} \mathrm{H}_{24} \mathrm{O}_{2}$ & 296.4 & 11 & 3.67 & 10.4 & \\
\hline BPA & $\mathrm{C}_{15} \mathrm{H}_{16} \mathrm{O}_{2}$ & 228.1 & 120 & 3.32 & 10.2 & \\
\hline
\end{tabular}

EDC: endocrine disruptors; $\log \mathrm{K}_{\mathrm{ow}}$ : octanol-water partition coefficient; SMZ: sulfamethoxazole; TMP: trimethoprim; DCF: diclofenac; E1: estrone; E2: $17 \beta$-estradiol; EE2: $17 \alpha$-ethinylestradiol; BPA: bisphenol-A.

(Hichrom 5, Berkshire, UK), acetonitrile/ $\mathrm{HCl} 0.1 \%$ as mobile phase. Analyses were carried out in a programmed gradient: increase of 10 to $100 \%$ acetonitrile in $10 \mathrm{~min}$, returning to $10 \%$ in $4 \mathrm{~min}$. The initial flow was $1.4 \mathrm{~mL} \mathrm{~min}^{-1}$ and after $5 \mathrm{~min}$ the flow was increased to $2.0 \mathrm{~mL} \mathrm{~min}^{-1}$. The column temperature was kept at $35^{\circ} \mathrm{C}$.

\section{Method validation parameters}

\section{Selectivity}

The interference of matrix compounds was assessed by retention times $\left(\mathrm{t}_{\mathrm{R}}\right)$, UV spectra, and peak purity tests for all endocrine disruptors compounds in both standard solutions and in the fortified matrix. The parallelism between the calibration curves obtained in both solvent and spiked matrices was also considered.

\section{Statistical analysis in the study of linearity}

The linearity of the method was checked in the range of 0.8-160 $\mu \mathrm{g} \mathrm{L} \mathrm{L}^{-1}$ with a set of seven different mixtures of endocrine disruptors standards $(0.8 ; 1.6 ; 8.0 ; 16.0 ; 32.0$, $80.0 ; 128.0$ and $160.0 \mu \mathrm{g} \mathrm{L}^{-1}$ ), all solutions were analyzed in triplicate. Calibration curves were obtained for each target compound by matrix-matched calibration method by plotting the analyte concentration versus the peak area at the selected absorption wavelengths. 
The range of linearity to the target compounds was evaluated based on the steps reported in Barbosa and coworkers' study. ${ }^{16,17}$

Visual inspection of the residual plots was performed and in cases of inconclusive visual inspection, it was performed Hartley's $F_{\text {max }}$ test to evaluate homoscedasticity. The estimation of the regression parameters by ordinary least squares (OLS) approach requires that the regression residuals follow a normal distribution. In case of heteroscedasticity, the equations of the calibration curves and correlation coefficient (r) were obtained by the method of weighted least squares (WLS). ${ }^{16,17}$ Finally, the evaluation of the adjustment of the calibration equations was conducted according to the Student's $t_{\mathrm{r}}$-test for lack of fit.

The Hartley's $F_{\text {max }}$ test was conducted by calculus of the $F$ statistics by equation 1 and compared with the critical value $F_{(\mathrm{f}=\mathrm{m}-1 ; \mathrm{k})}$ of Hartley's $F$ table. ${ }^{18,19}$

$$
F_{\text {max }}=\frac{\mathrm{s}_{\max }^{2}}{\mathrm{~s}_{\text {min }}^{2}}
$$

where $\mathrm{s}_{\max }^{2}$ and $\mathrm{s}_{\min }^{2}$ are the largest and the smallest variances of the regression, respectively. $F$ values less than or equal to the $F$ critical value show that the regression residuals are homoscedastics.

The $t_{\mathrm{r}}$-test to verify the linear model fit for the calibration curves was performed by calculus of $t$ statistic by equation 2 and compared with the critical value $t_{\text {crit }}$ to $(n-2)$ degrees of freedom and $95 \%$ of level of confidence, where $r$ is the correlation coefficient and $n$ is the number of calibration levels. When the $t_{\mathrm{r}}$ values were larger than or equal to the critical values, the equation was considered adequate for the calibration curves..$^{20-22}$

$t_{\mathrm{r}}=|\mathrm{r}| \sqrt{\frac{\mathrm{n}-2}{1-\mathrm{r}^{2}}}$

\section{Significance of regression parameters}

After obtaining the adjusted calibration equations it was finally assessed the statistical significance of the regression parameters using the $t$-test. The calculations were carried out for the $t$-values for each regression parameter by equations 3 and $4 .{ }^{19}$

$$
\begin{aligned}
& t_{\text {calc, b }}=\frac{|\mathrm{b}-1|}{\mathrm{s}_{\mathrm{b}}} \\
& t_{\text {calc,a }}=\frac{|\mathrm{a}-0|}{\mathrm{s}_{\mathrm{a}}}
\end{aligned}
$$

where $\mathrm{b}$ is the $y$-intercept; $\mathrm{s}_{\mathrm{b}}$ is the standard deviation of b-values; $a$ is the slope of the calibration curve; $s_{a}$ is the standard deviation of a-values

The equations 5 and 6 were used in the calculations of the standard deviations for the parameters estimated by OLS regression. ${ }^{19}$ The term $\mathrm{s}_{\mathrm{y} / \mathrm{x}}$ is the standard error of regression and $\overline{\mathrm{x}}$ is the the average of the values.

$$
\begin{aligned}
& \mathrm{s}_{\mathrm{b}}=\frac{\mathrm{s}_{\mathrm{y} / \mathrm{x}}}{\sqrt{\sum_{\mathrm{i}=1}^{\mathrm{n}}\left(\mathrm{x}_{\mathrm{i}}-\overline{\mathrm{x}}\right)^{2}}} \\
& \mathrm{~s}_{\mathrm{a}}=\mathrm{s}_{\mathrm{y} / \mathrm{x}} \sqrt{\frac{1}{\mathrm{n}}+\frac{\overline{\mathrm{x}}^{2}}{\sum_{\mathrm{i}=1}^{\mathrm{n}}\left(\mathrm{x}_{\mathrm{i}}-\overline{\mathrm{x}}\right)^{2}}}
\end{aligned}
$$

Limit of detection (LOD) and limit of quantification (LOQ)

The estimative of limit of detection (equation 7) and limit of quantification (equation 8) were determined based on the parameters of adjusted calibration curves, according to ICH guideline. ${ }^{23}$

$$
\begin{aligned}
& \mathrm{LOD}=\frac{3.3 \sigma}{\mathrm{a}} \\
& \mathrm{LOQ}=\frac{10 \sigma}{\mathrm{a}}
\end{aligned}
$$

where $\sigma$ is the standard deviation of the response based on the standard deviation of the blank; $a$ is the slope of the calibration curve.

\section{Accuracy and precision}

The precision of the method was assessed by repeatability. Accuracy was assessed by recovery experiments running with three replicates of spiked samples in levels $0.8,1.6$ and $16.0 \mu \mathrm{g} \mathrm{\textrm {L } ^ { - 1 }}$ for all compounds. The repeatability was reported by relative standard deviation (RSD, in percentage) and accuracy by recovery percentage (Rec), calculated by equations 9 and 10 , respectively. In equation 9 , the term $\mathrm{s}_{\mathrm{r}}$ is the standard deviation of repeatability.

$\operatorname{RSD}(\%)=\frac{\mathrm{s}_{\mathrm{r}}}{\overline{\mathrm{x}}} \times 100$

$\operatorname{Rec}(\%)=\frac{\mathrm{C}_{1}-\mathrm{C}_{2}}{\mathrm{C}_{3}}$

where $C_{1}$ is the average concentration determined in the fortified sample; $\mathrm{C}_{2}$ is the concentration determined in the unfortified sample (blank sample); and $\mathrm{C}_{3}$ is the added concentration to the sample. 


\section{Sample collection}

The described method was applied to the determination of endocrine disruptors in wastewater samples from wastewater treatment plants. Duplicate grab wastewater samples were collected between September 2013 and March 2015 from two full-scale WWTPs located in the state of Ceará, a semi-arid zone in Brazil. The two STPs (A and B) comprised upflow anaerobic sludge blanket (UASB) with post-chlorination disinfection. Additional details regarding these STPs are given in Table 2. For each STP, five influent and effluent samples were analyzed in order to determine the estrogens removal.

Table 2. Details of the wastewater treatment plants studied

\begin{tabular}{lccc}
\hline STP & $\begin{array}{c}\text { Treatment } \\
\text { technology }\end{array}$ & $\begin{array}{c}\text { Resident } \\
\text { inhabitants }\end{array}$ & Additional information \\
\hline A & $\begin{array}{c}\text { UASB with } \\
\text { post-chlorination } \\
\text { disinfection }\end{array}$ & 6145 & $\begin{array}{c}\text { working volume }=25 \mathrm{~m}^{3} ; \\
\text { mean flow rate }=8.9 \mathrm{~L} \mathrm{~s}^{-1}\end{array}$ \\
\hline B & $\begin{array}{c}\text { UASB with } \\
\text { post-chlorination } \\
\text { disinfection }\end{array}$ & 3917 & mean flow rate $=7.47 \mathrm{~L} \mathrm{~s}^{-1}$ \\
\hline
\end{tabular}

STP: sewage treatment plants; UASB: upflow anaerobic sludge blanket.

The samples were collected in glass flasks, transferred to $1 \mathrm{~L}$ amber glass bottles and preserved by the addition of $10 \mathrm{~mL} \mathrm{~L}^{-1}$ formaldehyde. Then, the samples were transported to the laboratory in cooling boxes and were prepared for analysis within $48 \mathrm{~h}$. Formaldehyde was also used in the method validation, and no interference was observed. ${ }^{5,24}$

\section{Results and Discussion}

\section{Calibration curves}

\section{Selectivity}

The selectivity was observed by association of the $\mathrm{t}_{\mathrm{R}}$, peak purity tests, UV spectra, and the parallelism of the calibration curves. Figure 1 shows the overlap chromatograms from prepared samples obtained in matrix and $160 \mu \mathrm{g} \mathrm{L}^{-1}$ spiked matrix. It can be observed no interference for the seven studied compounds.

The DAD detects the absorption in ultraviolet (UV) to visible (Vis) region, it has multiple photodiode arrays to obtain information over a wide range of wavelengths at one time. If two analytes have different spectra, it is possible to distinguish them using HPLC-DAD even if they have similar $t_{R}$. Another common DAD application is in determination of the compound purity, wherein the

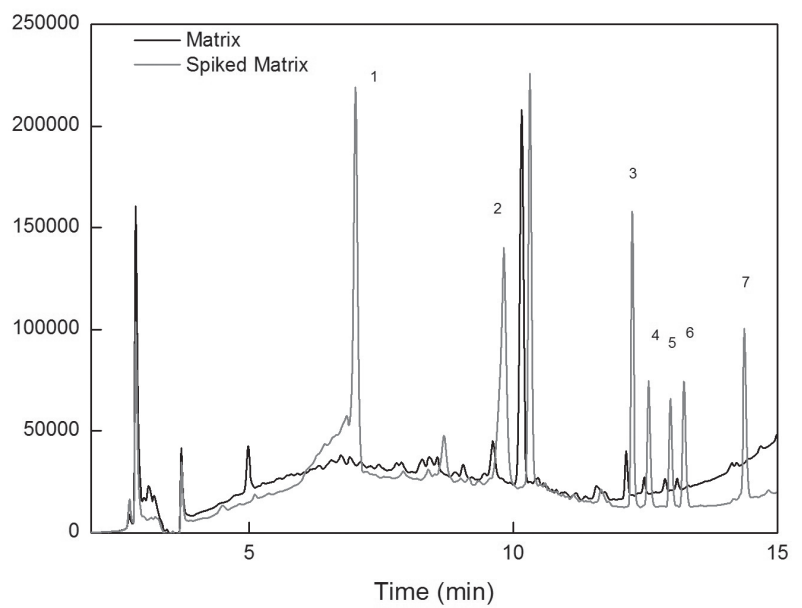

Figure 1. Overlap chromatograms from prepared samples obtained in matrix and $160 \mu \mathrm{g} \mathrm{L}^{-1}$ spiked matrix.

software calculates the rate of absorption through the peak.

The peak purity tests performed by the HPLC-DAD software revealed that all peaks had their purity levels higher than $99 \%$, independent of the matrix (Table 3).

Table 3. Peak purity and similarity tests performed by the HPLC-DAD software

\begin{tabular}{lcccc}
\hline & Compound & $\begin{array}{c}\text { Retention } \\
\text { time / min }\end{array}$ & Similarity / \% & Purity / \% \\
\hline 1 & TMP & 6.906 & 96.49 & 99.96 \\
2 & SMZ & 9.59 & 88.79 & 100 \\
3 & BPA & 12.12 & 98.42 & 100 \\
4 & E2 & 12.46 & 96.78 & 100 \\
5 & EE2 & 12.85 & 96.67 & 100 \\
6 & E1 & 13.08 & 96.07 & 100 \\
7 & DCF & 14.21 & 96.48 & 100 \\
\hline
\end{tabular}

TMP: trimethoprim; SMZ: sulfamethoxazole; BPA: bisphenol-A; E2: $17 \beta$-estradiol; EE2: 17 $\alpha$-ethinylestradiol; E1: estrone; DCF: diclofenac.

The similarity is calculated from the comparison of the compound's absorption spectra in the matrix and in standard solutions. The resulting spectrum is a graph where absorption versus wavelength $(\mathrm{nm})$ is related. Absorption in UV-Vis of organic molecules is restricted to certain functional groups (chromophores), which contain valence electrons with low excitation energy. UV-Vis spectra can be used for the qualitative identification of molecules and atomic species, since they are characteristic of a certain molecular structure.

In this study, it was possible to observe similarity level higher than $96 \%$ for all studied compounds. It can be seen in Figure 2 the unambiguous comparisons of the overlapping absorption spectra for the compounds studied in matrix with 

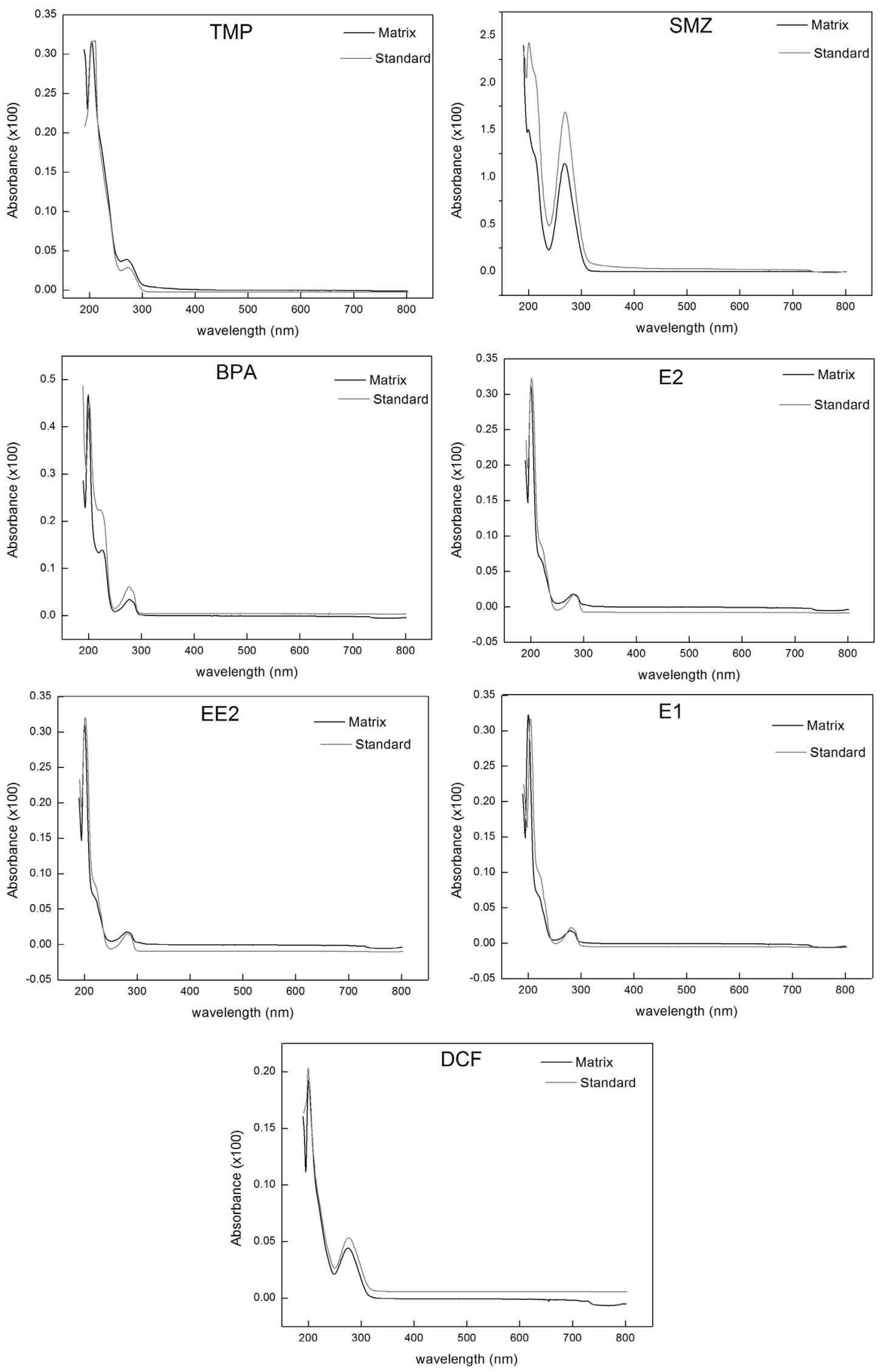

Figure 2. Overlap absorption spectra from the standard compounds and compounds present in matrix sample. 
the standards. Then, these observations guarantee that the method is selective for the seven endocrine disruptors and can be used for monitoring purposes of wastewater samples.

\section{Sensibility, linearity and range}

The residual plots visual inspection and Hartley's $F_{\max }$ test indicated lack of fit in linear range from 0.8 to $160 \mu \mathrm{g} \mathrm{\textrm {L } ^ { - 1 }}$ for all studied compounds, however, for the 1.6-80.0 $\mu \mathrm{g} \mathrm{L}^{-1}$ considered range, it was possible to observe that OLS was more appropriate than WLS method for BPA and SMZ compounds (Table 4). The E2 compound showed homoscedastic behavior in a wider linear range (1.6-128 $\left.\mu \mathrm{g} \mathrm{L}^{-1}\right)$, as well as TMP compound $\left(0.8-80 \mu \mathrm{g} \mathrm{L}^{-1}\right)$. For DCF, E1 and EE2 compounds, 8.0-160.0 $\mu \mathrm{g} \mathrm{L}^{-1}$ considered range it was more appropriate. The different behavior indicated the need for careful selection of the most adequate model to express the analytical curve and the need for assuring the reliability of the used method. Figure 3 shows simple residuals plots of two compounds.

The linear models for calibration curves showed good fit for all compounds in the selected range, confirmed by the coefficients of correlation $r$ ranging from 0.9926 to 0.9999 and $t_{\mathrm{r}}$-test, which indicated that $t_{\mathrm{r}}$-values were higher than $t_{\text {crit }}$ values for $(n-2)$ degrees of freedom at $95 \%$ confidence level. ${ }^{21,22}$

The analytical method showed higher sensibility for TMP and SMZ compounds, which can be seen by the slope values from calibration curves in Table 4. This might happen due to the high amount of chromophore groups (unsaturated organic groups that absorb in the ultraviolet and visible regions) present in the molecular structure of TMP and SMZ compounds compared to the other studied compounds besides the presence of nitrogen and sulfur atoms, which have nonbonding electrons in their structures, giving them a greater capacity for absorption of radiation in the range of 170 to $250 \mathrm{~nm}$, then increasing the UV-Vis detector sensibility for TMP and SMZ compounds. At the same time, the hormones E1, E2 and EE2 showed the lower values, probably due to the presence of only one phenol and hydroxyl groups in their molecular structures with most of its structures consisting of single bonds, $\mathrm{C}-\mathrm{C}$ and $\mathrm{C}-\mathrm{H}$, which do not absorb radiation in the UV-Vis. ${ }^{14}$

Table 4. Results of the global calibration statistical analysis

\begin{tabular}{lccccccc}
\hline EDC & Calibration equation & $\mathrm{r}$ & Range $/\left(\mu \mathrm{g} \mathrm{L}^{-1}\right)$ & $t_{\mathrm{r}}$ & $t_{\text {crit }(\alpha=0.05)}$ & $F_{\text {calc }}$ & $F_{\text {crit }(\mathrm{f}=\mathrm{n}-1 ; \mathrm{k})}$ \\
\hline BPA & $y=2431.1 x+5699.7$ & 0.9998 & $1.6-80.0$ & 86.59 & 3.18 & 6.96 & $202(\mathrm{k}=5)$ \\
DCF & $y=2014.8 x-2704.2$ & 0.9926 & $8-160.0$ & 16.37 & 2.78 & 37.86 & $266(\mathrm{k}=6)$ \\
E1 & $y=1394.6 x-907.6$ & 0.9983 & $8-160.0$ & 33.98 & 2.78 & 46.67 & $266(\mathrm{k}=6)$ \\
E2 & $y=1176.9 x+4702.8$ & 0.9994 & $1.6-128.0$ & 57.71 & 2.78 & 23.05 & $266(\mathrm{k}=6)$ \\
EE2 & $y=1098.9 x-3563.6$ & 0.9971 & $8-160.0$ & 26.02 & 2.78 & 28.90 & $266(\mathrm{k}=6)$ \\
SMZ & $y=4522.1 x+20879.3$ & 0.9999 & $1.6-80.0$ & 14.60 & 3.18 & 29.08 & $202(\mathrm{k}=5)$ \\
TMP & $y=4366.4 x-1081.7$ & 0.9990 & $0.8-80.0$ & 31.04 & 2.36 & 117.6 & $403(\mathrm{k}=6)$ \\
\hline
\end{tabular}

EDC: endocrine disruptors; r: correlation coefficient; $t_{\mathrm{r}}$ : Student's $t$ parameter calculated; $t_{\text {crit } \alpha=0.05)}$ : critical Student's $t$ parameter for a significance level of $0.05 ; F_{\text {calc }}$ : calculated $F$ parameter; $F_{\text {crit (f=n-1; })}$ : critical $F$ parameter for $\mathrm{n}-1$ degrees of freedom and k data set; BPA: bisphenol-A; DCF: diclofenac; E1: estrone; E2: 17ß-estradiol; EE2: 17 $\alpha$-ethinylestradiol; SMZ: sulfamethoxazole; TMP: trimethoprim.
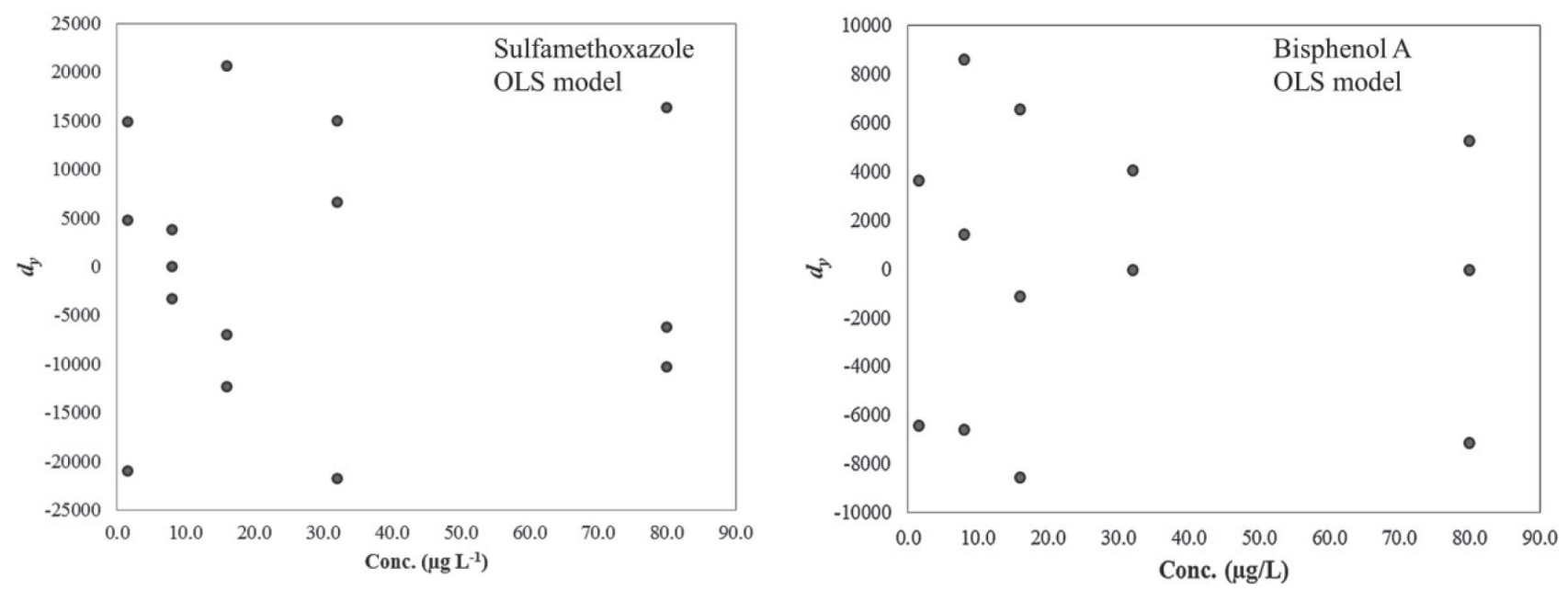

Figure 3. Residual plots for SMZ and BPA compounds. 
Despite DCF and BPA compounds also presenting chromophore groups in its molecular structure, the DAD detector showed lower sensibility to them compared to TMP and SMZ. This might happen since DCF and BPA have high $\log \mathrm{K}_{\mathrm{ow}}$ (octanol-water partition coefficient) values, which might imply to them a higher affinity to SPE cartridges in the sample preparation step, decreasing the efficiency of methanol extraction step and then decreasing the amount of these compounds present in the sample, thereby decreasing the intensity of absorption for such compounds since quantity of material is directly proportional to the absorption intensity detector.

Table 5 shows the $t$-test results for significance of regression parameters: slopes and intercepts. It can be seen that the $t$ calculated values for most of the regression parameters were greater than the critical $t$ values, with exception for E1, EE2, DCF and TMP compounds using $95 \%$ confidence level and $(n-2)$ degrees of freedom. These corrected calibration equations were used to predict analyte concentrations in subsequent validation studies as in the analyzed wastewater treatment samples.
Limit of detection (LOD), limit of quantification (LOQ), accuracy and precision

The estimated LOD and LOQ for the analytes are

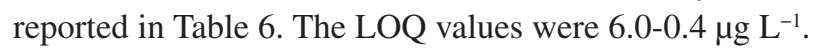
Despite the high values of LOQ found in the present study, when compared to other studies using more sensitive techniques, such as LC-MS/MS, ${ }^{9}$ the values were justified, since the environmental samples analyzed showed high levels of the compounds studied.

The values found were similar to those found by Pessoa et al., ${ }^{5}$ which studied the hormones E1, E2 and EE2 using derivatization techniques for sample preparation followed by GC-MS analysis. These authors found values of $0.12 ; 0.04$ and $4.7 \mu \mathrm{g} \mathrm{L}^{-1}$, respectively.

Almost all EDCs showed recovery rates of approximately $68-106 \%$, to the lowest fortification level. All analytes showed RSD below $24 \%$.

SMZ showed low recovery levels, such as 18.78 and $23.89 \%$ for 16 and $1.6 \mu \mathrm{g} \mathrm{L}-1$ levels, respectively. According to Vidal et al., ${ }^{6}$ the low recoveries of SMZ compound by Strata-X cartridges are related to the weak interaction

Table 5. Results for significance of regression parameters: slopes and intercepts

\begin{tabular}{lcclc}
\hline EDC & Calibration equation & $t_{\text {calc,b }}$ & $t_{\text {calc, }}$ & $t_{\text {crit }(v ; 1-\alpha=0.95)}$ \\
BPA & $y=(2431.1 \pm 27.09) x+(5699.7 \pm 1066.12)$ & 89.72 & 5.34 & 3.18 \\
DCF & $y=(2014.8 \pm 49.63) x$ & 16.36 & 0.24 & 2.18 \\
E1 & $y=(1394.6 \pm 56.23) x$ & 33.95 & 0.24 & 2.78 \\
E2 & $y=(1176.9 \pm 20.19) x+(4702.8 \pm 1280.09)$ & 58.26 & 3.67 & 2.78 \\
EE2 & $y=(1098.9 \pm 1.49) x$ & 26.00 & 0.93 & 3.18 \\
SMZ & $y=(4522.1 \pm 5.98) x+(20879.3 \pm 235.35)$ & 756.14 & 3.21 & 3.18 \\
TMP & $y=(4366.4 \pm 33.47) x$ & 132.4 & 2.27 & \\
\hline
\end{tabular}

EDC: endocrine disruptors; $t_{\text {calc, },}:$ Student's $t$ parameter calculated to $y$-intercept; $t_{\text {calc, a: }}$ : Student's $t$ parameter calculated to slope; $t_{\text {crit }}(v ; 1-\alpha=0.95):$ critical Student's $t$ parameter for a confidence level of 95\%; BPA: bisphenol-A; DCF: diclofenac; E1: estrone; E2: 17 $\beta$-estradiol; EE2: 17 $\alpha$-ethinylestradiol; SMZ: sulfamethoxazole; TMP: trimethoprim.

Table 6. Results from the estimated LOD, LOQ, accuracy and precision

\begin{tabular}{|c|c|c|c|c|c|c|c|c|}
\hline \multirow{2}{*}{ EDC } & \multirow{2}{*}{$\begin{array}{l}\mathrm{LOD} / \\
\left(\mu \mathrm{g} \mathrm{L}^{-1}\right)\end{array}$} & \multirow{2}{*}{$\begin{array}{c}\text { LOQ / } \\
\left(\mu \mathrm{g} \mathrm{L}^{-1}\right)\end{array}$} & \multicolumn{3}{|c|}{$\operatorname{Rec} / \%$} & \multicolumn{3}{|c|}{ RSD / \% } \\
\hline & & & $16 \mu \mathrm{g} \mathrm{L}^{-1}$ & $1.6 \mu \mathrm{g} \mathrm{L}^{-1}$ & $0.8 \mu \mathrm{g} \mathrm{L}^{-1}$ & $16 \mu \mathrm{g} \mathrm{L}^{-1}$ & $1.6 \mu \mathrm{g} \mathrm{L}^{-1}$ & $0.8 \mu \mathrm{g} \mathrm{L}^{-1}$ \\
\hline BPA & 0.5 & 1.6 & 89.37 & 179.55 & 69.64 & 2.31 & 0.21 & 11.08 \\
\hline DCF & 0.4 & 1.2 & 106.01 & 134.10 & 138.32 & 13.91 & 2.87 & 13.45 \\
\hline E1 & 0.8 & 2.8 & 52.30 & 84.34 & 62.60 & 7.85 & 5.84 & 11.93 \\
\hline E2 & 0.3 & 1.2 & 74.36 & 173.71 & 96.43 & 2.27 & 11.28 & 16.14 \\
\hline EE2 & 1.8 & 6.0 & 67.40 & 143.29 & 74.67 & 1.31 & 7.90 & 1.18 \\
\hline SMZ & 0.1 & 0.4 & 18.78 & 23.89 & 68.64 & 23.38 & 0.32 & 14.97 \\
\hline TMP & 0.2 & 0.8 & 158.22 & 181.09 & 205.53 & 0.68 & 12.43 & 7.40 \\
\hline
\end{tabular}

EDC: endocrine disruptors; LOD: limit of detection; LOQ: limit of quantification; Rec: recovery; RSD: relative standard deviation; BPA: bisphenol-A; DCF: diclofenac; E1: estrone; E2: 17ß-estradiol; EE2: 17 $\alpha$-ethinylestradiol; SMZ: sulfamethoxazole; TMP: trimethoprim. 
between SMZ compounds and the Strata-X cartridges polymeric material. Furthermore, the SMZ has the higher solubility comparing to the other studied compounds, and then this endocrine disruptor seems to have more affinityfor aqueous instead of solid phase. TMP compound had different behavior, showing higher recovery values between $205.53-158.22 \%$. For this compound the matrix effect might be more pronounced.

Accuracy, in the form of recovery measures (in percentage), is always considered adequate within certain limits (associated with precision values). In cases where the analyte is found at trace level in the sample, as in this study $\left(0.80,1.6\right.$ and $\left.16 \mu \mathrm{g} \mathrm{L}^{-1}\right)$, and there is analytical complexity, the minimum and maximum recovery values are less restrictive than the traditional 70-120\% range, being considered as reasonable recovery values between 50 and $120 \%$, with a precision of up to $15 \% .25-27$

It was not developed specific studies to estimate the matrix effect in the present research. However, factors associated with the nature of the analyte (physicalchemical properties) and the chromatographic system (injection system, column and detector) might influence the increasing of chromatographic response induced by the matrix, explaining recovery levels above $120 \%$ for some analytes in the present study. The mechanisms related to the chromatographic system are not clear, there are few studies ${ }^{25}$ that deal with the matrix effect in the HPLC-DAD system.

\section{Occurrence of endocrine disruptors in influent and effluent samples}

It is well known that most of the endocrine disruptors are introduced to environment from the discharge of wastewater treatment plants since these treatments technologies are not specifically designed to remove these

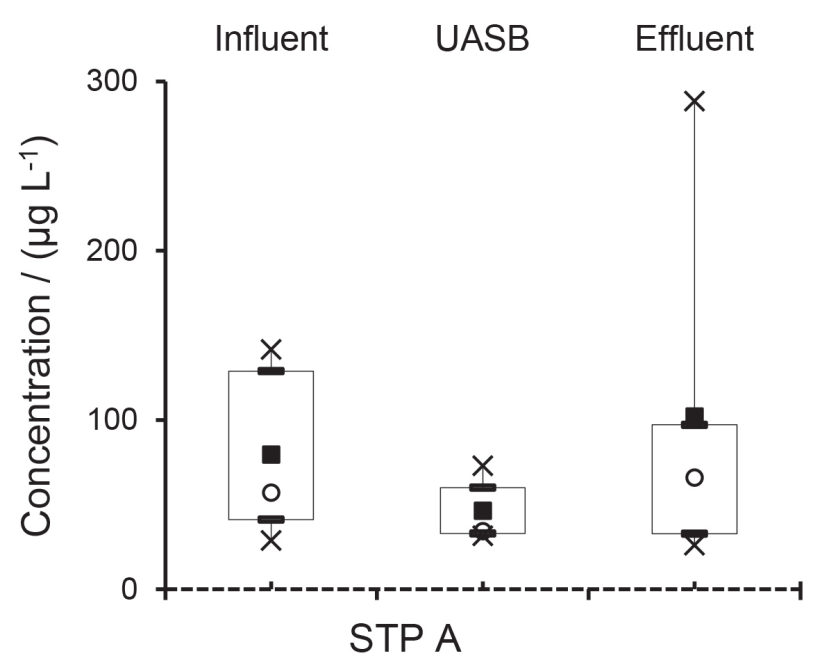

compounds. As a consequence, it is extremely important to investigate and understand the fate of EDC within treatment facilities in order to increase removal efficiency and prevent their disposal in surface waters and the contamination of drinking water and ground water.

The distribution of each endocrine disruptors concentrations which were measured in raw and treated (before and after chlorination step) wastewater from two STP $(n=26)$ is shown in Figures 4-10.

\section{Removal of hormones}

According to Figure 4, it is possible to see that neither STP A nor B is efficient to remove E1 compound. In both studied STPs, the mean in the effluent (102.07 and $26.44 \mu \mathrm{g} \mathrm{L}^{-1}$, respectively) were higher than influent (79.54 and $25.27 \mu \mathrm{g} \mathrm{L}^{-1}$, respectively), this might due to the conversion of E2 and EE2 into E1 before it could be transformed further. ${ }^{28-31}$

It can also be noticed in STP A, an interesting behavior of E1 concentration level through the treatment steps. After UASB process there was removal in E1 concentration, however, after chlorine disinfection step there was an increase in that concentration. This probably might be due the oxidation-reduction (redox) reaction, since E1 compound under anaerobic conditions $(\mathrm{R}=\mathrm{O})$ might be reduced to $\mathrm{E} 2$ compound ( $\mathrm{R}-\mathrm{OH})$, which might return to the oxidized form (E1) after chlorine disinfection process.

In terms of $\mathrm{E} 2$ compound, the maximum concentration found in STP A was $613.83 \mu \mathrm{g} \mathrm{L}^{-1}$, and the mean concentrations: $175.09,141.57$ and $102.50 \mu \mathrm{g} \mathrm{L}^{-1}$ for influent, post-UASB and effluent (after chlorination), respectively (Figure 5). The mean E2 removal was approximately $42 \%$. For STP B, the E2 maximum

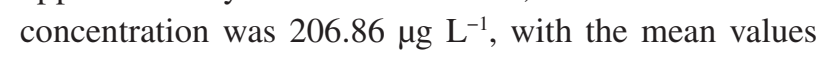
of the influent, post-UASB and effluent of $83.49,54.85$

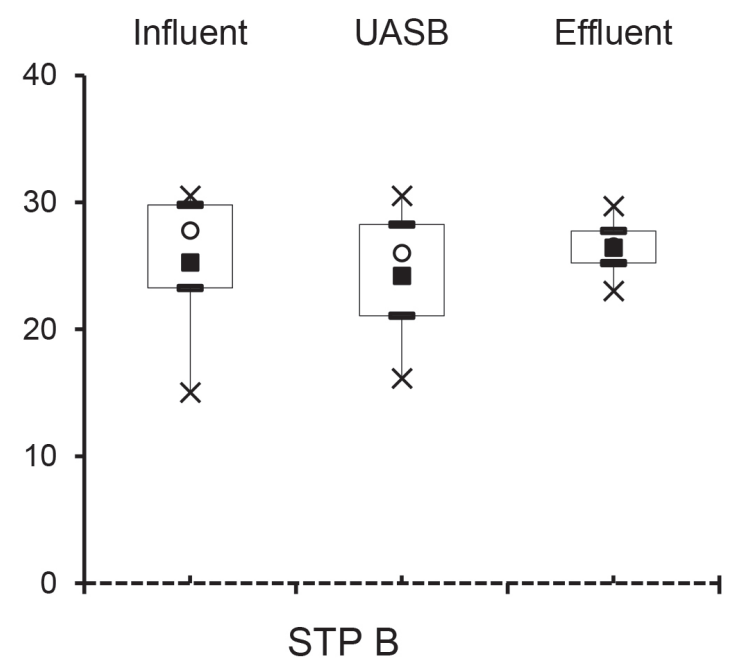

Figure 4. Boxplots of the influent, post-UASB and effluent E1 concentrations. 
and $43.87 \mu \mathrm{g} \mathrm{L}^{-1}$, respectively (Figure 5). The mean E2 removal in the STP B was better than STP A, with removal of $55.30 \%$.

For the EE2 hormone, the maximum concentration found in the STP A was $192.89 \mu \mathrm{g} \mathrm{L}^{-1}$, with the mean values of the influent, post-UASB and effluent of 102.19; 85.48 and $59.18 \mu \mathrm{g} \mathrm{L}^{-1}$, respectively (Figure 6). In terms of total removal, a value of $42.1 \%$ was obtained. For STP B, the EE2 maximum concentration was $188.82 \mu \mathrm{g} \mathrm{L}^{-1}$, with concentrations of influent, post-UASB and effluent were $71.71 ; 102.20$ and $14.79 \mu \mathrm{g} \mathrm{L}^{-1}$, respectively (Figure 6). In terms of total removal, the STP B proved to be more efficient than the STP A, with a $79.4 \%$ removal.

The concentration values for the estrogenic steroids (E1, E2 and EE2) found in the present study is higher than those found in the literature, ${ }^{5}$ which evaluated the occurrence and removal efficiency of four estrogenic hormones in five

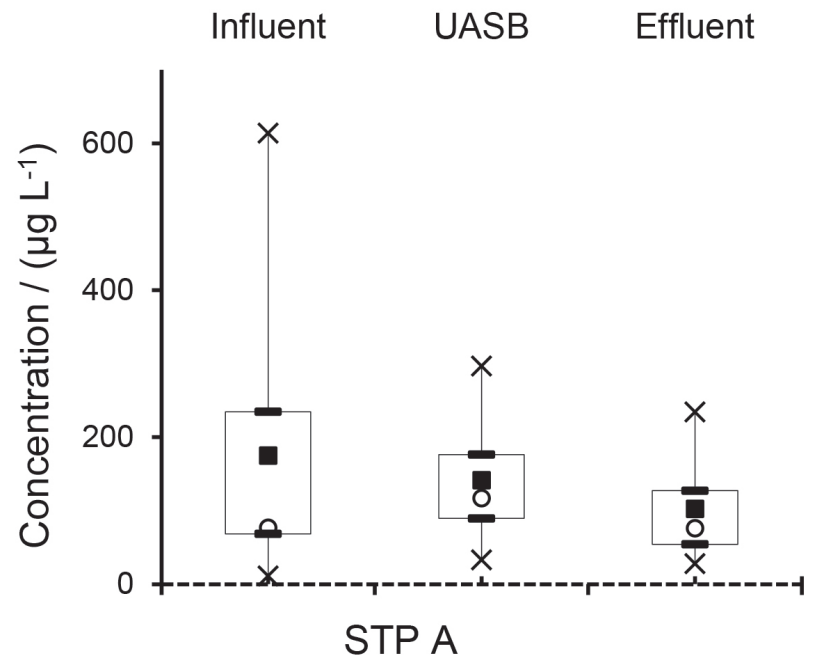

biological STPs, located in the state of Ceará, Brazil. The authors found mean influents concentrations of $0.57,0.14$ and $0.42 \mu \mathrm{g} \mathrm{L} \mathrm{L}^{-1}$ for E1, E2 and EE2, respectively.

Out of Brazil, average concentrations of estrogenic steroids in effluent of sewage treatment plants (STPs) are lower than this study. In Italian STPs it was found 0.08, 0.01 , and $0.05 \mu \mathrm{g} \mathrm{L}-1$, for E1, E2 and EE2, respectively. The concentrations of E2 in influents of Japanese STPs ranged from 0.03 to $0.09 \mu \mathrm{g} \mathrm{L}^{-1}$ and 0.02 to $0.1 \mu \mathrm{g} \mathrm{\textrm {L } ^ { - 1 }}$ in autumn and summer seasons, respectively. ${ }^{10}$

\section{Removal of pharmaceuticals}

For the TMP antibiotic, the maximum concentration

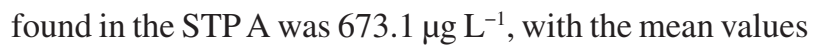
of the influent, post-UASB and effluent of 187.01, 79.44 and $60.43 \mu \mathrm{g} \mathrm{L} \mathrm{L}^{-1}$, respectively (Figure 7). In terms of total removal, a value of $67.7 \%$ was found. For STP B, the

Figure 5. Boxplots of the influent, post-UASB and effluent E2 concentrations.
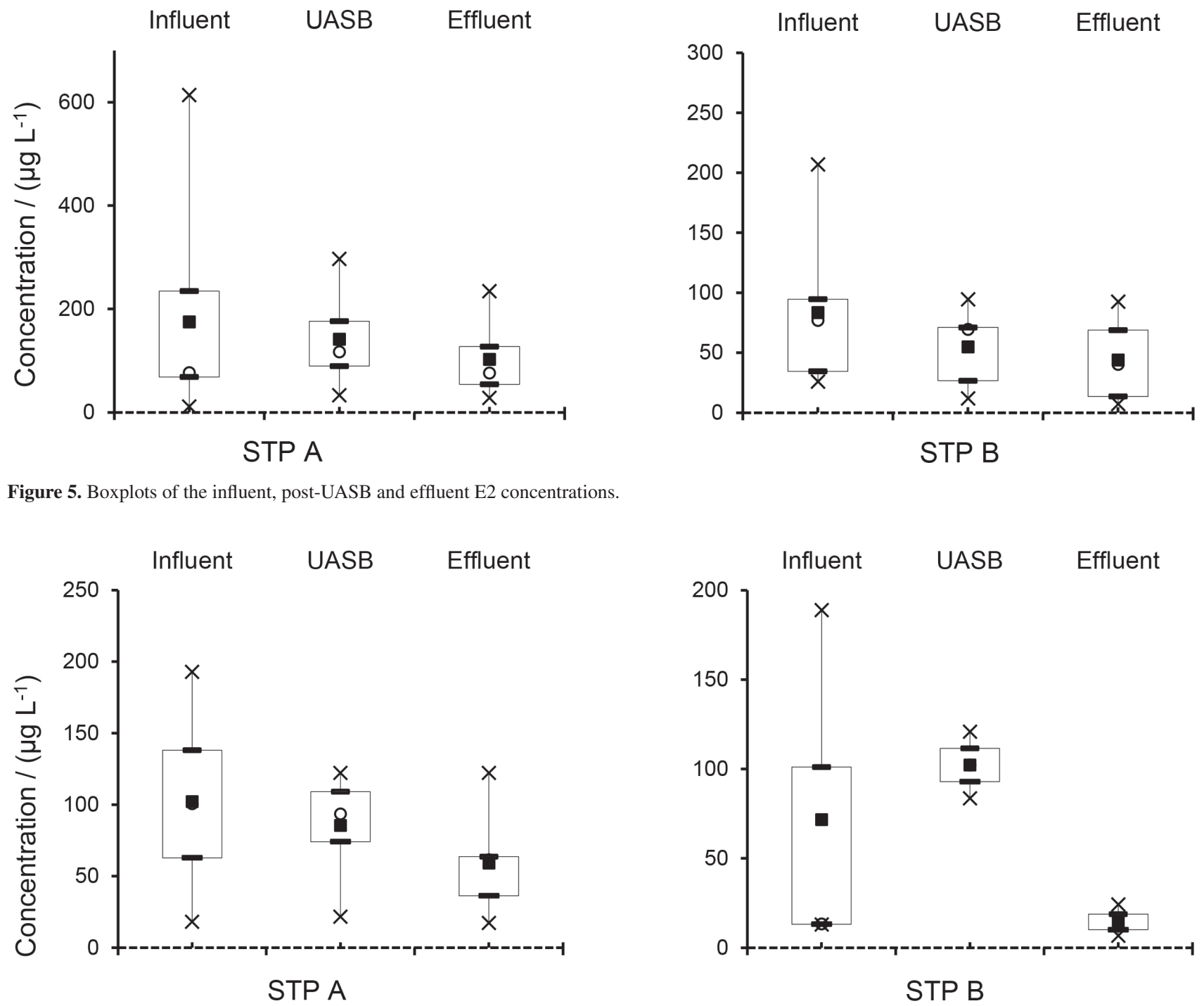

Figure 6. Boxplots of the influent, post-UASB and effluent EE2 concentrations. 
maximum value of the TMP was $128.45 \mu \mathrm{g} \mathrm{L} \mathrm{L}^{-1}$, and the concentrations of influent, post-UASB and effluent were 35.92, 36.10 and $40.83 \mu \mathrm{g} \mathrm{L}{ }^{-1}$, respectively (Figure 7). In terms of total removal, STP B was not efficient.

For the SMZ antibiotic, the maximum concentration found in the STP A was $619.26 \mu \mathrm{g} \mathrm{L}^{-1}$, with the mean values of the influent, post-UASB and effluent of 215.17; 161.53 and $71.98 \mu \mathrm{g} \mathrm{L}^{-1}$, respectively (Figure 8 ). In terms of total removal, a value of $66.6 \%$ was found. Different behavior was found in STP B, where there was initially an increase in SMZ concentration after UASB reactor and small removal after chlorination step. Thus, there was a global removal of $32.3 \%$.

For the anti-inflammatory DCF, the maximum concentration found in the STP A influent was $594.27 \mu \mathrm{g} \mathrm{L}^{-1}$, with influent, post-UASB and effluent mean concentrations of 218.97; 201.61 and $235.34 \mu \mathrm{g} \mathrm{L^{-1 }}$, respectively (Figure 9). In terms of total removal, STP B was not efficient. The DCF maximum value of $153.65 \mu \mathrm{g} \mathrm{L}^{-1}$

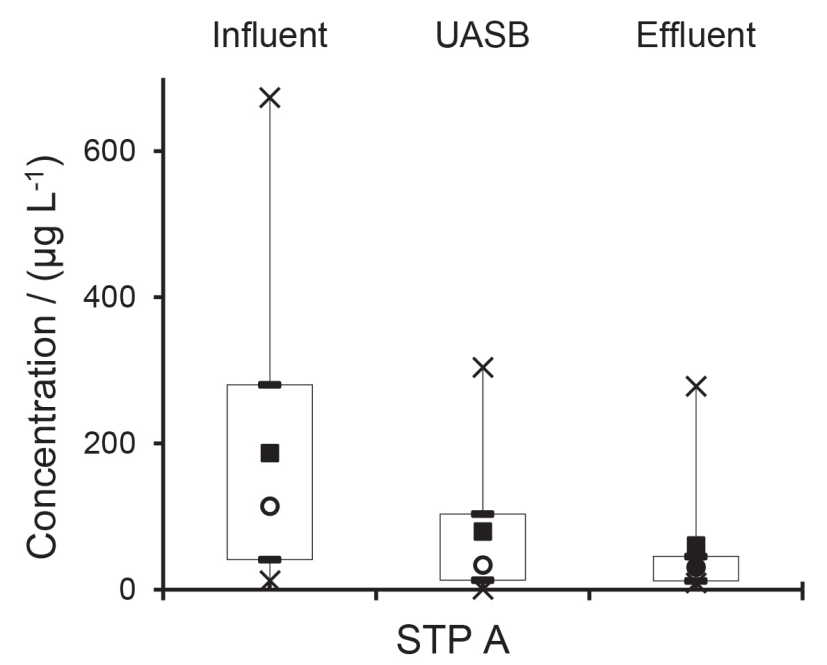

was found for the STP B, with the influent, post-UASB and effluent mean concentrations of $71.50 ; 18.39$ and $28.81 \mu \mathrm{g} \mathrm{L}^{-1}$, respectively (Figure 9). In terms of total removal, the STP B proved to be much more efficient than the STP A, with a removal percentage of $59.7 \%$.

Rivera-Jaimes et al. ${ }^{32}$ studied the occurrence of pharmaceuticals in wastewater treatment plants of Cuernavaca, the capital of the state of Morelos (Mexico). The authors found the following WWTP influent concentration levels range: $2.4-2.5 \mu \mathrm{g} \mathrm{L}{ }^{-1}$ for diclofenac, 0.13-0.79 $\mu \mathrm{g} \mathrm{L}^{-1}$ for trimethoprim and $0.12-0.16 \mu \mathrm{g} \mathrm{L}^{-1}$ for sulfamethoxazole.

\section{Removal of BPA}

For the plastic compound BPA, the STP A presented in its influent a maximum concentration of $140.26 \mu \mathrm{g} \mathrm{L}^{-1}$, with the influent, post-UASB and effluent mean concentrations 87.12; 77.46 and $65.44 \mu \mathrm{g} \mathrm{L}{ }^{-1}$, respectively (Figure 10). In

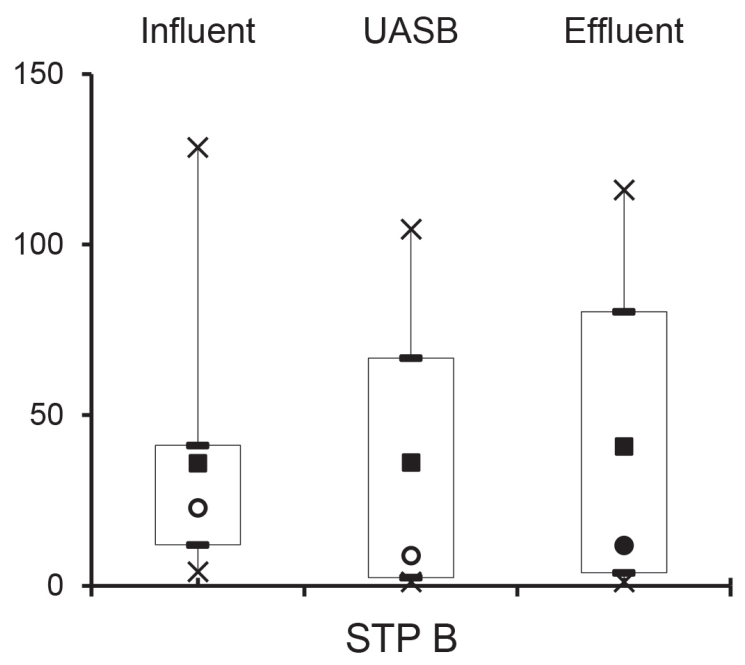

Figure 7. Boxplots of the influent, post-UASB and effluent TMP concentrations.

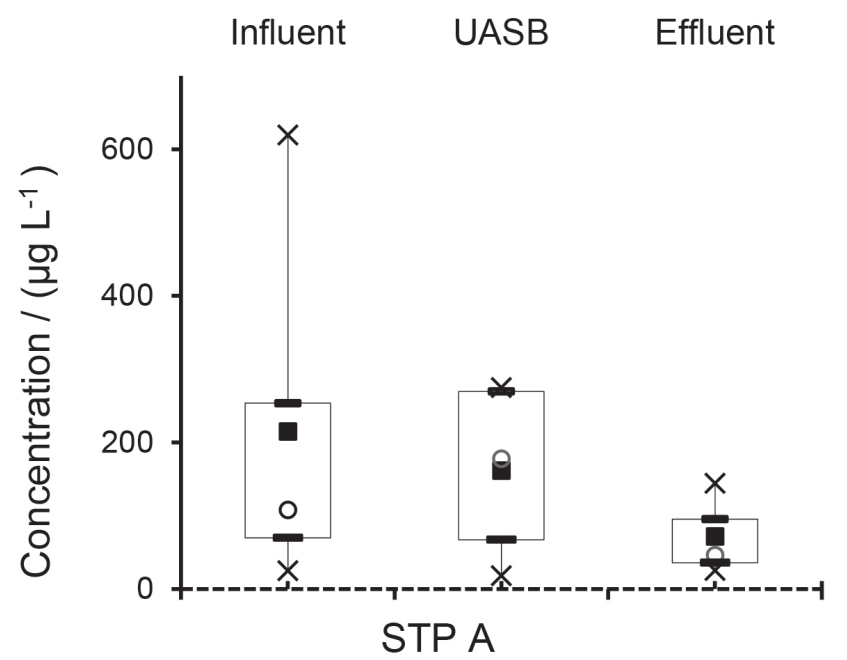

Figure 8. Boxplots of the influent, post-UASB and effluent SMZ concentrations.

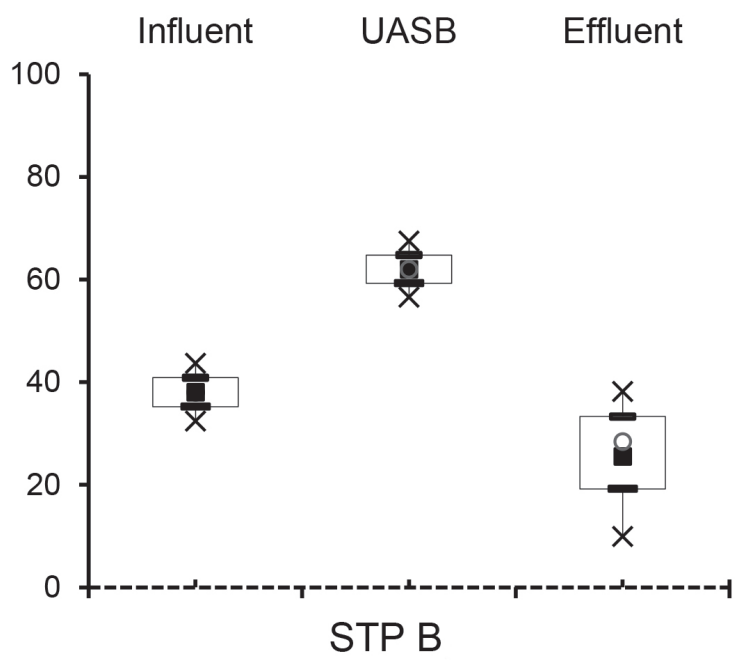




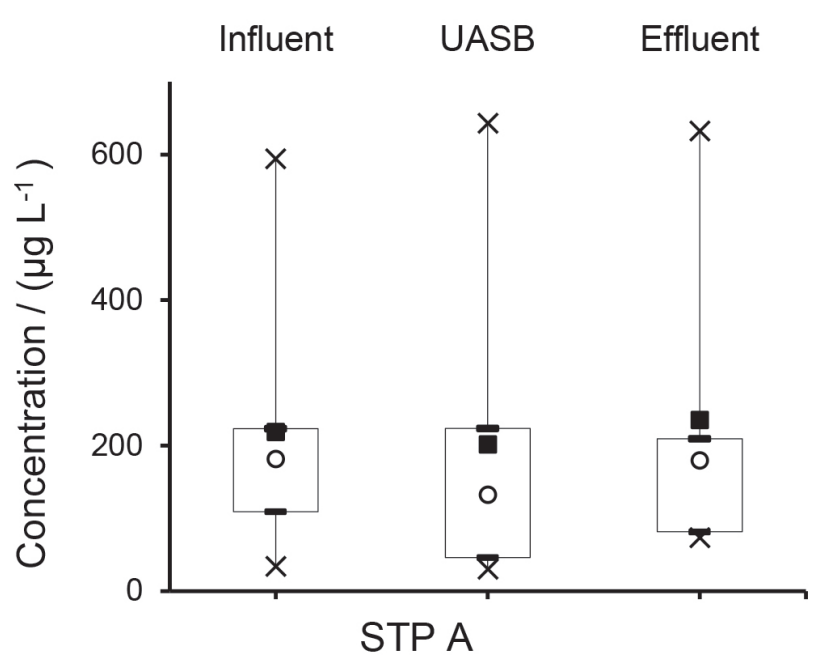

Figure 9. Boxplots of the influent, post-UASB and effluent DCF concentrations.

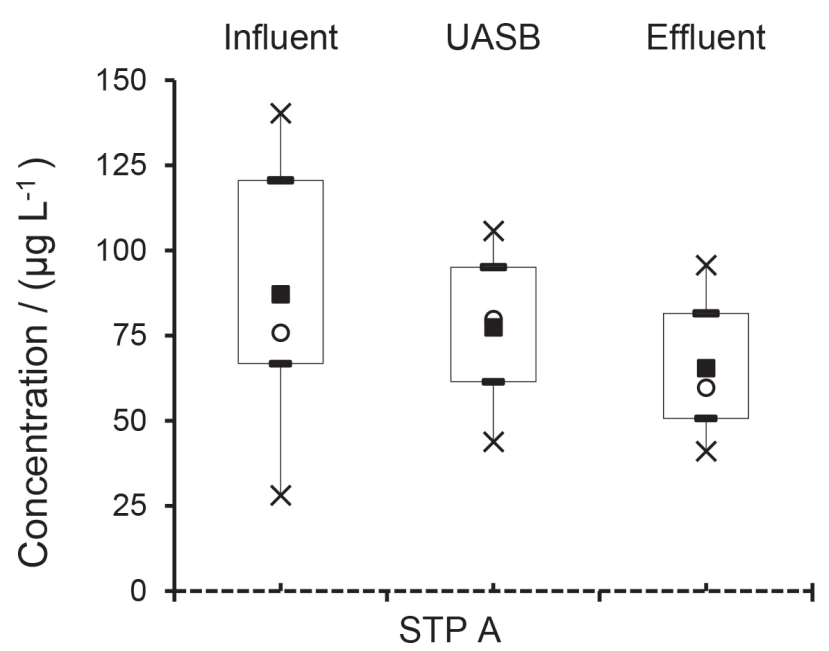

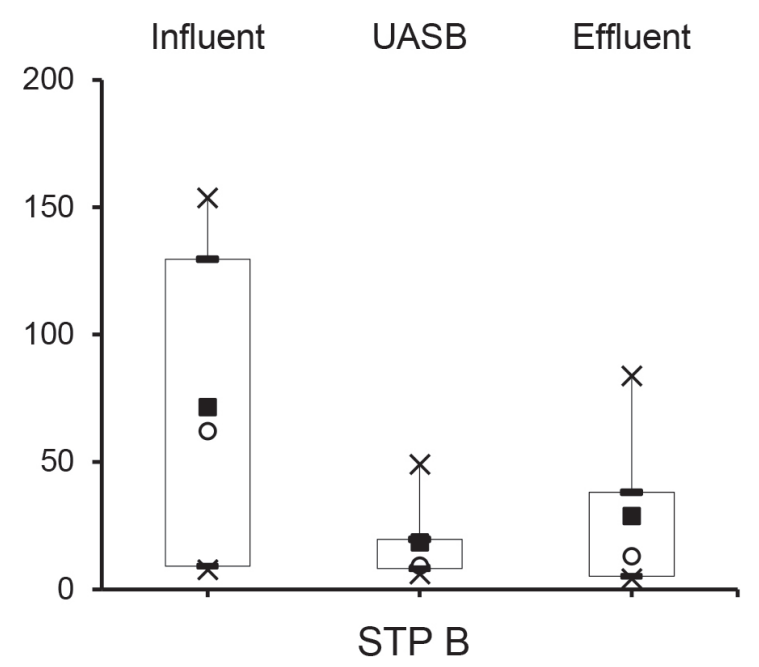

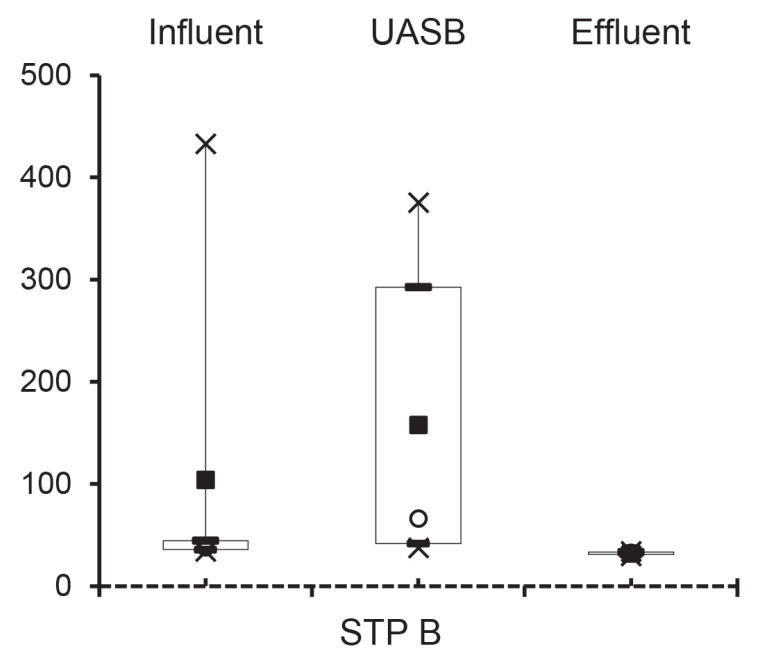

Figure 10. Boxplots of the influent, post-UASB and effluent BPA concentrations.

terms of total removal, a value of $24.9 \%$ was found. For STP B, treatment was better than STP A, with removal of $69.3 \%$.

\section{Conclusions}

Although the occurrence of endocrine disruptors in the wastewater matrices has been extensively investigated in developed countries, it needs to be further studied in developing countries, where the proportion of non treated wastewaters is still very large. This study investigates the occurrence of seven endocrine disruptors from different chemical classes in sewage of the Fortaleza region, located at state of Ceará (Brazil) during two consecutive years. Seven investigated EDCs were consistently found at relevant concentrations (reaching the $\mu \mathrm{g} \mathrm{L}^{-1}$ level) in all STPs studied.

The removal efficiency behavior of the two STPs were different, despite both have the same biological treatment technology, due the differences between the STPs, such as hydraulic holding time, type of inoculum, and EDC influent concentration. Even after biological treatment, the effluents still present considerable amounts of all EDCs, even in high concentrations when compared to those reported in the literature, requiring a post-treatment step for the elimination of these compounds from the effluents before they are discarded into the water bodies.

\section{Acknowledgments}

The authors would like to thank CAPES (Coordination of Higher Level Personal Improvement) for the scholarship and CNPq for the financial support (process: 577000/2008-2). We also would like to thank the personnel of the water treatment plants in Ceará, Brazil (CAGECE) for their cooperation with all aspects of this study. This study was funded by the CNPq, project No. 577000/2008-2. 


\section{Author Contributions}

Carla B. Vidal was responsible for the conceptualization, data curation, formal analysis, funding acquisition, investigation, methodology, project administration, resources and writing original draft; Pablo G. A. Barbosa for the data curation, formal analysis and writing review and editing; Germana P. Pessoa for the conceptualization and data curation; Patrícia C. Buarque for the conceptualization and data curation; José G. S. Nascimento for the data curation and writing original draft; Antônio L. Farias Filho for the data curation; Mário S. Paz for the formal analysis and writing original draft; André B. dos Santos for the funding acquisition, project administration, resources and supervision; Rivelino M. Cavalcante for the writing review and editing; Ronaldo F. Nascimento for the conceptualization, project administration, resources, writing original draft, review and editing.

\section{References}

1. Adeel, M.; Song, X.; Wang, Y.; Francis, D.; Yang, Y.; Environ. Int. 2017, 99, 107.

2. Lapworth, D. J.; Baran, N.; Stuart, M. E.; Ward, R. S.; Environ. Pollut. 2012, 163, 287.

3. Buarque, P. M. C.; de Lima, R. B. P.; Vidal, C. B.; Buarque, H. L. B.; Firmino, P. I. M.; dos Santos, A. B.; Eng. Sanit. Ambient. 2019, 24, 667 .

4. de Oliveira, F. F.; Moura, K. O.; Costa, L. S.; Vidal, C. B.; Loiola, A. R.; do Nascimento, R. F.; ACS Omega 2020, 5 , 3346

5. Pessoa, G. P.; de Souza, N. C.; Vidal, C. B.; Alves, J. A. C.; Firmino, P. I. M.; Nascimento, R. F.; dos Santos, A. B.; Sci. Total Environ. 2014, 490, 288.

6. Vidal, C. B.; Feitosa, A. V.; Pessoa, G. P.; Raulino, G. S. C.; Oliveira, A. G.; dos Santos, A. B.; Nascimento, R. F.; Desalin. Water Treat. 2015, 54, 156.

7. Vidal, C. B.; dos Santos, A. B.; do Nascimento, R. F.; Bandosz, T. J.; Chem. Eng. J. 2015, 259, 865.

8. Vidal, C. B.; Seredych, M.; Rodríguez-Castellón, E.; Nascimento, R. F.; Bandosz, T. J.; J. Colloid Interface Sci. 2015, 449, 180.

9. Omar, T. F. T.; Aris, A. Z.; Yusoff, F. M.; Mustafa, S.; Talanta 2017, 173, 51

10. Ashfaq, M.; Li, Y.; Wang, Y.; Qin, D.; Rehman, M. S. U.; Rashid, A.; Yu, C.-P.; Sun, Q.; Chemosphere 2018, 204, 170.

11. Castiglioni, S.; Bagnati, R.; Calamari, D.; Fanelli, R.; Zuccato, E.; J. Chromatogr. A 2005, 1092, 206.
12. Paz, M.; Correia-Sá, L.; Vidal, C. B.; Becker, H.; Longhinotti, E.; Domingues, V. F.; Delerue-Matos, C.; J. Environ. Sci. Health, Part B 2017, 52, 48.

13. Pessoa, G. P.; dos Santos, A. B.; de Souza, N. C.; Alves, J. A. C.; do Nascimento, R. F.; Quim. Nova 2012, 35, 968.

14. Msagati, T. A.; Nindi, M. M.; Talanta 2004, 64, 87.

15. Babić, S.; Ašperger, D.; Mutavdžić, D.; Horvat, A. J. M.; Kaštelan-Macan, M.; Talanta 2006, 70, 732.

16. Barbosa, P. G. A.; Martins, F. I. C. C.; Lima, L. K.; Milhome, M. A. L.; Cavalcante, R. M.; do Nascimento, R. F.; Food Anal. Methods 2018, 11, 466.

17. Martins, F. I. C. C.; Barbosa, P. G. A.; Zocolo, G. J.; do Nascimento, R. F.; Chromatographia 2018, 81, 677.

18. Konieczka, P.; Namiesnik, J.; Quality Assurance and Quality Control in the Analytical Chemical Laboratory, $2^{\text {nd }}$ ed.; CRC Press: Boca Raton, 2018.

19. Danzer, K.; Currie, L. A.; Pure Appl. Chem. 1998, 70, 993.

20. Bazilio, F. S.; Bomfim, M. V. J.; Almeida, R. J.; Abrantes, S. M. P.; Accredit. Qual. Assur. 2014, 19, 195.

21. Cacoullos, T.; Stat. Probab. Lett. 2001, 54, 1.

22. Miller, J.; Miller, J. C.; Statistics and Chemometrics for Analytical Chemistry, $6^{\text {th }}$ ed.; Pearson Education: Quebec, 2010.

23. International Conference on Harmonization (ICH); Validation of Analytical Procedures: Text and Methodology Q2 (R1); ICH: Geneva, 2005.

24. Cavalcante, R. M.; de Andrade, M. V. F.; Marins, R. V.; Oliveira, L. D. M.; Microchem. J. 2010, 96, 337.

25. Oshita, D.; Jardim, I. C. S. F.; Quim. Nova 2015, 38, 1273.

26. Ribani, M.; Bottoli, C. B. G.; Collins, C. H.; Jardim, I. C. S. F.; Melo, L. F. C.; Quim. Nova 2004, 27, 771.

27. Alcântara, D. B.; Fernandes, T. S. M.; Nascimento, H. O.; Lopes, A. F.; Menezes, M. G. G.; Lima, A. C. A.; Carvalho, T. V.; Grinberg, P.; Milhome, M. A. L.; Oliveira, A. H. B.; Becker, H.; Zocolo, G. J.; Nascimento, R. F.; Food Chem. 2019, 298, 124958.

28. Starling, M. C. V. M.; Amorim, C. C.; Leão, M. M. D.; J. Hazard. Mater. 2019, 372, 17.

29. Czajka, C. P.; Londry, K. L.; Sci. Total Environ. 2006, 367, 932.

30. Carballa, M.; Omil, F.; Lema, J. M.; Llompart, M.; García-Jares, C.; Rodríguez, I.; Gómez, M.; Ternes, T.; Water Res. 2004, 38, 2918.

31. Shi, J.; Fujisawa, S.; Nakai, S.; Hosomi, M.; Water Res. 2004, $38,2323$.

32. Rivera-Jaimes, J. A.; Postigo, C.; Melgoza-Alemán, R. M.; Aceña, J.; Barceló, D.; López de Alda, M.; Sci. Total Environ. 2018, 613-614, 1263. 